\title{
PERSPEKTIF KARYAWAN PERBANKAN \\ PADA KOMUNIKASI INTERNAL DENGAN TWO-WAY SYMMETRICAL COMMUNICATION DAN INTERNAL MARKETING
}

\author{
Mia Angeline \\ Marketing Communication Department, Faculty of Economic and Communication, BINUS University \\ Jln. K.H. Syahdan No. 9, Palmerah, Jakarta Barat 11480 \\ f.angeline@gmail.com
}

\begin{abstract}
The article investigates the internal communication in the two branches of foreign banks in Kelapa Gading from the perspectives of two-way symmetrical communication and internal marketing. The second problem investigated is the effectiveness of the use of email as a means of internal communication. Data were collected through interviews and literature. The results showed that the perception of employees not in accordance with the concept of two-way communication and internal marketing, but this policy has led the organization to these concepts. In the use of email, employee perceptions still see that the email is an effective internal communication media despite having many weaknesses.
\end{abstract}

Keywords: internal communication, two-way communication, internal marketing

\begin{abstract}
ABSTRAK
Artikel meneliti mengenai komunikasi internal pada dua bank asing di cabang Kelapa Gading dari sudut pandang two-way symmetrical communication dan internal marketing. Masalah kedua yang diteliti adalah efektivitas penggunaan email sebagai media komunikasi internal. Data dikumpulkan melalui wawancara dan studi pustaka. Hasil menunjukkan bahwa persepsi karyawan belum sesuai dengan konsep two-way communication dan internal marketing, namun kebijakan organisasi telah mengarah pada kedua konsep ini. Dalam penggunaan email, persepsi karyawan masih melihat bahwa email adalah media komunikasi internal yang efektif walaupun memiliki berbagai kelemahan.
\end{abstract}

Kata kunci: komunikasi internal, two-way communication, internal marketing 


\section{PENDAHULUAN}

Komunikasi internal terjadi secara terus menerus di dalam organisasi dan mencakup mulai dari chat informal hingga managed communication (Welch \& Jackson, 2007, hal. 178). Komunikasi internal yang tidak diatur dengan baik dapat menyebabkan berbagai masalah seperti kurangnya efektivitas dan efisiensi kerja, ketidakpuasan di antara pegawai, hingga kekacauan internal di dalam tubuh organisasi. Tantangan utama yang dihadapi organisasi terkait dengan komunikasi internal seperti dikemukakan oleh Quirke adalah bagaimana memilih di antara sekian banyak alternatif media komunikasi yang ditawarkan oleh kemajuan teknologi. Tidak semua media akan memberikan hasil yang efektif sesuai dengan situasi yang dialami oleh organisasi (Hewitt, 2006, hal. 78). Setiap organisasi perlu mengatur komunikasi internalnya, baik secara vertikal maupun horizontal, agar efisiensi dan kinerja pegawai dapat maksimal. Dari komunikasi internal yang baik, maka akan tercipta komunikasi eksternal yang dapat mendukung jalinan relasi dan persepsi citra publik terhadap organisasi tersebut.

Konsep lain yang tidak kalah penting dan perlu diaplikasikan oleh semua perusahaan adalah internal marketing. Perusahaan telah menyadari pentingnya berinvestasi untuk menciptakan global recognition akan nama produk atau perusahaan. Untuk mendapatkan corporate brand yang kuat, maka diperlukan internal marketing. Identitas merek perusahaan (corporate brand's identity) dialami dan dirasakan oleh para stakeholder melalui setiap poin kontak yang mereka alami dengan perusahaan. Karena itu komunikasi internal sangat diperlukan dalam mengomunikasikan posisi brand dan harapan pelanggan agar karyawan mengetahui dan melaksanakan peran mereka sebagai brand builders (Papasolomou \& Vrontis, 2006, hal. 39). Lebih jauh, Papasolomou dan Vrontis juga menyatakan logika di balik melihat karyawan sebagai pelanggan internal adalah dengan memuaskan kebutuhan dari pelanggan internal maka perusahaan akan lebih siap untuk menghasilkan servis berkualitas yang diharapkan oleh pelanggan eksternal.

Dari banyaknya media komunikasi internal yang dipakai dalam perusahaan, email adalah media yang paling banyak dipakai oleh karyawan (Hewitt, 2006, hal. 78). Hewitt juga menyatakan email selain memiliki segi positif juga memiliki dampak negatif untuk perusahaan. Dengan kurangnya pengecekan serta overload dari server, maka penggunaan email dapat menyebabkan information overload dan rasa bergantung pada teknologi sehingga karyawan melupakan pentingnya face to face communication. Karena itu, dalam penelitian ini juga ingin diketahui apakah email memang berkontribusi terhadap komunikasi internal yang efektif. Atau sebaliknya, email menyebabkan kontraproduktivitas dari karyawan. Penelitian akan dilaksanakan secara kualitatif dan bertempat di kantor cabang bank UOB Buana dan Citibank di Kelapa Gading.

Sedangkan rumusan masalah dalam penelitian ini adalah: 1) seperti apa persepsi staf terhadap komunikasi internal dalam organisasi sesuai dengan teori two-way symmetrical communication dan internal marketing; dan 2) seperti apa persepsi staf email adalah media komunikasi internal yang efektif di dalam organisasi. berikut.

Dari fenomena dan rumusan masalah di atas, maka tujuan penelitian terangkum dalam tabel

Tabel 1 Tujuan Penelitian

\begin{tabular}{cl}
\hline No. & \multicolumn{1}{c}{ Tujuan } \\
\hline T1 & $\begin{array}{l}\text { Mempelajari persepsi staf terhadap komunikasi internal telah sesuai dengan teori two-way } \\
\text { symmetrical communication dan internal marketing }\end{array}$ \\
T2 & $\begin{array}{l}\text { Mempelajari persepsi staf industri perbankan mengenai apakah email merupakan media } \\
\text { komunikasi internal yang efektif }\end{array}$ \\
\hline
\end{tabular}




\section{Urgensi Penelitian}

Sebelum perusahaan dapat memberikan servis yang terbaik kepada konsumen, harus dimulai dari memberikan servis terbaik dari pelanggan internal dahulu. Jika konsep ini tidak disepakati oleh seluruh karyawan, pelayanan kepada konsumen juga akan terganggu dan berujung pada menurunnya citra perusahaan dan penjualan produk. Untuk mendapatkan konsep dan persepsi yang sama dari seluruh karyawan, dibutuhkan media komunikasi internal yang efektif dan dapat dipersepsikan sama oleh seluruh karyawan perusahaan. Selain itu, media internal yang tidak efektif juga dapat menyebabkan kurangnya motivasi dan efektivitas kerja karyawan.

Karena itulah penelitian ini diharapkan dapat memberikan gambaran mengenai persepsi karyawan terhadap komunikasi internal di perusahaan tempat mereka bekerja. Jika persepsi karyawan telah sesuai dengan teori two-way symmetrical communication dan internal marketing, kemungkinan besar karyawan memiliki kepuasan dan kinerja yang efektif, serta dapat memberikan pelayanan terbaik kepada konsumen. Selain itu, secara jangka panjang, penelitian ini diharapkan dapat menjadi langkah pertama untuk mencari solusi yang menjembatani gap persepsi antara karyawan dan manajemen di bidang komunikasi internal.

\section{Komunikasi Internal}

Didefinisikan oleh Orsini sebagai strategi yang digunakan karyawan dalam suatu organisasi untuk berkomunikasi satu sama lain (Steyn, Steyn, \& van Rooyen, 2011, hal. 132). Komunikasi internal yang efektif dapat memberikan makna bagi pekerjaan dan profesi, membuat karyawan merasa terhubung, serta dapat meningkatkan produktivitas. Karena itu menurut Van Heerden, kebijakan komunikasi internal harus mendorong tipe komunikasi yang jujur, terbuka, terkait dengan pekerjaan, dan bersifat dua arah antara pimpinan dan bawahan serta didukung oleh lingkungan internal yang akomodatif (Steyn, Steyn, \& van Rooyen, 2011, hal. 132).

Namun tidak semua organisasi dapat menerapkan komunikasi internal yang efektif, dan menyebabkan karyawan merasa tidak puas dengan kualitas dan kuantitas informasi yang mereka terima. Karyawan juga menginginkan untuk menjadi bagian dari suatu proyek besar dan melihat yang mereka kerjakan bisa membawa perubahan untuk organisasi (Papasolomou \& Vrontis, 2006). Karena itu, karyawan menginginkan interaksi lebih dengan manajemen, kepuasan kerja, dan tanggung jawab serta kekuasaan untuk mengambil keputusan yang lebih besar.

\section{Two-way Symmetrical Internal Communication}

Karyawan dalam organisasi melakukan dan mempertahankan relasi interpersonal, yang membutuhkan derajat interaksi dan ketergantungan satu sama lain. Scholes, dikutip dalam (Papasolomou \& Vrontis, 2006) mengatakan kunci dari komunikasi adalah adanya pemahaman akan kebutuhan lawan bicara, sehingga sender dan receiver harus memiliki derajat pengertian yang sama.

Menurut Woodward, two way symmetrical internal communication bertujuan untuk mendapatkan pemahaman mutual dan untuk membangun dialog antar pihak-pihak serta memiliki efek yang seimbang. Dalam model komunikasi ini, komunikator menggunakan riset dan dialog untuk mengatur konflik, meningkatkan pemahaman dan membangun relasi (Steyn, Steyn, \& van Rooyen, 2011, hal. 133). Dalam model ini pula, kekuasaan dibagi secara merata antara organisasi dan publikpublik yang terkait, komunikasi bersifat timbal balik, dan seluruh pihak yang terlibat bersedia menyesuaikan sikap dan perilaku mereka agar tercapainya pemahaman bersama. Dari karakteristik tersebut, model two-way symmetrical ini mempunyai keuntungan dapat membangun budaya partisipatif di kalangan karyawan yang dapat meningkatkan motivasi dan kepuasan kerja karyawan (Steyn, Steyn, \& van Rooyen, 2011, hal. 133). 


\section{Internal Marketing}

Konsep ini muncul seiring dengan perubahan dari transaction marketing menjadi relationship marketing, yang menekankan pada pentingnya menjalin hubungan dengan publik internal dan eksternal dari organisasi. Sehingga dari konsep relationship marketing ini muncul konsep employeefocused internal marketing, yang fokus pada managemen relasi antara pimpinan dan karyawan (Steyn, Steyn, \& van Rooyen, 2011, hal. 133).

Menurut Gronroos, dikutip dalam (Papasolomou \& Vrontis, 2006), internal marketing adalah "payung" yang mencakup aktivitas internal dalam organisasi dan bertujuan untuk meningkatkan pelayanan dan mempertahankan orientasi melayani diantara sesama karyawan. Dengan kata lain internal marketing bertujuan untuk mengembangkan awareness di antara karyawan akan konsumen internal dan eksternal dalam organisasi.

Hubungan antarkaryawan yang mutual juga memiliki keuntungan, antara lain: organisasi mampu mempertahankan karyawan yang berkualitas dan memotong biaya untuk mencari dan melatih karyawan baru (Shekary, Moghadam, Adaryany, \& Moghadam, 2012). Implementasi internal marketing dalam organisasi adalah melalui penyebaran konsep bahwa sesama karyawan adalah konsumen internal yang juga perlu dipenuhi kebutuhannya dan memiliki standar kepuasan sendiri.

\section{Electronic Mail (email)}

Dipakai sebagai media komunikasi internal sehari-hari dalam organisasi. Salah satu kelebihan email adalah kecepatan dan kemampuan untuk mengirimkan pesan ke banyak penerima dalam satu waktu, dan kelemahan utama email adalah tanda-tanda nonverbal yang dapat dibaca dari pengirim pesan, sehingga sering terjadi kesalahpahaman dalam mempersepsi pesan. Stevens dan McElhill mengatakan komunikasi tertulis bukanlah medium yang efektif yang dapat digunakan untuk menyampaikan pesan di semua situasi, dan bukan cara terbaik untuk memotivasi karyawan (Hewitt, 2006, hal. 80). Email tidak dapat menggantikan komunikasi tatap muka dan tidak dapat menumbuhkan kepercayaan antara pengirim dan penerima, sehingga dalam konsep komunikasi internal dan internal marketing perlu diteliti lebih mendalam mengenai dampak email terhadap komunikasi internal organisasi.

\section{METODE PENELITIAN}

Untuk menjawab rumusan masalah, maka penelitian ini menggunakan metode kualitatif, agar dapat menangkap persepsi dan menginterpretasikan makna dari jawaban responden dengan lebih mendalam. Penelitian kualitatif ini memakai metode triangulasi, yaitu: Triangulasi data (menggunakan data kualitatif hasil wawancara staf organisasi); dan Triangulasi teori (menggunakan teori two-way symmetrical communication dan internal marketing serta email untuk menginterpretasikan data kualitatif hasil wawancara). Sedangkan untuk metode pengumpulan data, akan digunakan dua cara, yaitu: Wawancara, menggunakan tipe wawancara semistruktur kepada staf organisasi; dan Studi pustaka, menggunakan kajian teori dan jurnal ilmiah. Penelitian ini akan dilaksanakan di organisasi berikut, yaitu Bank UOB Buana dan Citibank cabang Kelapa Gading. 


\section{HASIL DAN PEMBAHASAN}

\section{Komunikasi Internal}

Pendekatan Komunikasi: baik di bank UOB Buana maupun Citibank, para staf dan kepala cabang sudah memahami pentingnya perhatian dan perlakuan yang baik kepada rekan kerja dan bawahan dengan tujuan untuk mencapai tujuan dari perusahaan. Namun secara praktik, para staf kedua bank ini masih merasa kebutuhan mereka belum terlalu diperhatikan dan masih kurangnya transparansi dari manajemen kantor pusat. Seperti dikutip dalam hasil wawancara dengan salah satu staf UOB Buana “....ada beberapa kebijakan yang seperti dipaksakan oleh pusat dan kurang melihat keadaan di lapangan.” Core Values: nilai-nilai inti yang diharapkan dan dipraktikan oleh UOB Buana adalah teamwork, trust dan respect sesama. Sedangkan nilai-nilai inti yang ada di Citibank adalah diversity dan teamwork. Internal media: media yang dipakai sehari-hari oleh staf UOB Buana adalah meeting tatap muka, email, telepon, Blackberry Messenger (BBM), newsletter, dan bulletin board. Sedangkan yang dipakai oleh staf di Citibank adalah telepon, email, BBM, meeting tatap muka, newsletter, chatting, internal site (Mysite), dan info TV. Open-door policy: para staf di bank UOB Buana dan Citibank keduanya telah mempraktikkan open-door policy didukung dengan tata ruang kantor yang terbuka. Staf Citibank merasakan adanya open environment dari organisasi mereka dan para staf bebas memberikan input mengenai organisasi. Alur Komunikasi: para staf dan kepala cabang di UOB Buana merasa pola komunikasi yang terjadi berupa top-down communication, dimana mereka menunggu keputusan yang dibuat manajemen pusat untuk diaplikasikan. Jika keputusan ini sulit untuk dilaksanakan di kantor cabang, para staf bebas untuk memberikan masukan mengenai keputusan tersebut. Sedangkan para staf di Citibank setuju pola komunikasi di cabang dan dalam tim berupa multi-directional, sementara kebijakan-kebijakan perusahaan dikomunikasikan secara top-down dari manajemen kantor pusat. Upward Communication: baik bank UOB Buana maupun Citibank mempunyai sarana formal bagi staf untuk menyarakan pendapat mereka agar didengar oleh manajemen pusat. Yang membedakan hanyalah situasi dan kedalaman isu yang membolehkan mereka menggunakan sarana ini. Di UOB Buana terdapat kebijakan "whistle blowing policy", jika terdapat masalah finansial atau masalah yang berkaitan dengan reputasi perusahaan, staf dapat melaporkan langsung kepada direksi. Sedangkan di Citibank terdapat sarana "voice of employee" dimana seluruh staf diwajibkan mengisi survei mengenai kepuasan dan lingkungan kerja. Voice of employee ini dilaksanakan setahun sekali. Sarana kedua adalah "employee's call center", jika staf merasa diperlakukan tidak adil, mendapat tekanan (bullying) atau pelecehan seksual di tempat kerja maka mereka bebas memanfaatkan sarana ini.

Dari hasil wawancara dengan narasumber mengenai komunikasi internal di atas, dapat disimpulkan bahwa komunikasi internal di UOB Buana dan Citibank belum sesuai dengan teori twoway symmetrical communication. Hal ini dikarenakan para staf dan middle management merasa belum seratus persen dilibatkan dalam pengambilan keputusan yang melibatkan perusahaan. Mereka merasa hanya menerima instruksi dari manajemen atas untuk diimplementasikan tanpa melihat keadaan di lapangan atau kantor cabang.

Ketidakseimbangan ini diperkecil oleh perusahaan dengan menggunakan tata ruangan yang terbuka dan suasana serta media internal yang terbuka. Namun dalam setiap organisasi pasti mempunyai budaya dan norma yang berbeda-beda, ada beberapa hal yang tetap tidak bisa dibicarakan terbuka oleh karyawan ke manajemen atas. Hal yang diterima dalam komunikasi internal ini secara terbuka adalah mengenai pekerjaan, sedangkan mengenai relasi personal dan konflik tidak dapat dikomunikasikan secara terbuka. Hal ini terlihat dari kebijakan di UOB "whistle blowing policy" hanya boleh digunakan untuk masalah finansial dan reputasi perusahaan. Sedangkan "voice of employee" Citibank mencakup topik yang lebih luas namun hanya diadakan setahun sekali. Ketika ditanya lebih dalam mengenai "voice of employee", hampir seluruh narasumber mengakui menjawab 
pertanyaan dengan positif karena takut jawaban mereka akan mempengaruhi penilaian kinerja atau pembagian bonus mereka dari atasan.

Dalam organisasi memang ada keputusan yang hanya dapat diambil oleh manajemen atas, namun sebagian besar keputusan lainnya perlu mendapat masukan dari karyawan atau kantor cabang yang berinteraksi langsung dengan konsumen terutama keputusan yang menyangkut konsumen. Keseimbangan dalam pengambilan keputusan ini sulit didapat jika masukan karyawan kurang atau dipaksakan.

\section{Internal Marketing}

Implementasi: staf bank UOB Buana sepakat bahwa implementasi konsep internal marketing belum merata di semua cabang sehingga tidak terasa maksimal. Beberapa staf di cabang UOB Buana Kelapa Gading harus mengalami rotasi ke kantor cabang lain, dan pengalaman implementasi ini dirasakan berbeda-beda oleh para staf yang telah mengalami rotasi ini. Secara mendasar telah diaplikasikan service level agreement antara staf sebagai standar pelayanan untuk karyawan internal. Sedangkan menurut staf Citibank cabang Kelapa Gading, konsep internal marketing telah diaplikasikan selama bertahun-tahun. Ada penekanan kepada staf bahwa jika karyawan internal puas maka konsumen eksternal juga akan merasakan kepuasan atas servis yang diberikan. Serta di Citibank ada pandangan yang menganggap semua karyawan adalah company's ambassador yang membawa citra perusahaan. Implementasi juga diperluas dengan diperbolehkannya divisi marketing dan tenaga penjualan untuk menjual produk Citibank kepada sesama karyawan.

Dari jawaban yang diberikan oleh semua narasumber, mereka sudah mengerti definisi internal marketing karena UOB Buana dan Citibank telah mensosialisasikan definisi dan kebijakan kepada seluruh karyawan. Akan tetapi, implementasi di kantor cabang masih bermasalah, terutama di UOB Buana. Para narasumber staf UOB Buana merasa satu-satunya acuan tertulis untuk implementasi internal marketing adalah service level agreement (SLA). Hal ini berarti konsep internal marketing belum menjadi budaya bekerja di UOB Buana. Karena jika sudah menjadi budaya, tidak dibutuhkan aturan tertulis untuk semua interaksi horizontal atau vertikal. Ketika ditanya lebih jauh mengenai SLA, narasumber dari UOB Buana menjawab di dalam SLA diatur mengenai sistem reward dan punishment jika karyawan menjalankannya. Sistem SLA ini adalah langkah awal bagi UOB Buana untuk menjadikan konsep internal marketing sebagai budaya perusahaan. Karena untuk implementasi yang belum merata, tetap dibutuhkan sistem reward dan punishment.

Sedangkan bagi narasumber dari Citibank, konsep internal marketing sudah menjadi budaya perusahaan yang terlihat dari definisi yang diberikan lebih mendetail. Tidak ada sistem reward dan punishment di Citibank mengenai sistem internal marketing. Sudah menjadi kebiasaan untuk memberikan pelayanan yang terbaik bagi rekan kerja, dan menurut pengakuan narasumber jika kita mendapatkan pelayanan yang baik maka kita akan terdorong untuk memberikan pelayanan yang terbaik pula.

\section{Penggunaan Email}

Baik staf UOB Buana dan Citibank setuju bahwa email memiliki berbagai kelebihan, di antaranya cepat dan dapat ditujukan kepada banyak orang dalam sekali pengiriman. Namun email juga memiliki beberapa kelemahan, seperti tidak mampu menunjukkan feedback nonverbal dan tidak dapat diketahui apakah penerima telah membaca email atau belum. Para staf kedua bank juga setuju email dapat mengarah pada kesalahpahaman karena penggunaan yang hanya berupa tulisan. Di UOB Buana ada masalah lain yaitu tidak semua karyawan yang memiliki akses internet dan alamat email kantor, sehingga karyawan yang tidak mendapat akses seperti ini merasa tidak dianggap oleh perusahaan. 
Dari segi efektivitas, email masih menjadi media internal yang diprioritaskan oleh narasumber dari kedua bank. Ketika ditanya efektivitas yang dimaksud adalah dari segi waktu, karena pekerjaan yang menumpuk setiap hari dan tidak mungkin untuk melakukan komunikasi tatap muka setiap waktu maka email dapat menggantikan komunikasi tersebut dengan sangat efektif.

Namun tidak semua hal cocok untuk dikomunikasikan melalui email. Ada beberapa hal yang lebih efektif melalui newsletter (jika menyangkut berita positif perusahaan), atau memo (jika menyangkut hal sangat penting yang mungkin terlewat dalam email), dan media-media lainnya. Jawaban seluruh narasumber mengenai email adalah media yang efektif karena email yang paling sering dipakai setiap hari dibanding media-media internal lainnya. Diperlukan sosialisasi dan pemakaian media internal lain yang lebih sering untuk menambah nilai efektivitas media internal, sehingga karyawan tidak tergantung dengan email perusahaan saja.

\section{SIMPULAN}

Dari hasil penelitian yang dilakukan kepada para staf di UOB Buana dan Citibank cabang Kelapa Gading maka dapat disimpulkan: pertama, persepsi staf di kedua bank ini belum sesuai dengan teori mengenai two-way symmetrical internal communication dan internal marketing, pembagian kekuasaan di Citibank belum terlihat merata karena sebagian besar keputusan masih bersifat top-down, tetapi persepsi staf Citibank dan implementasi kedua konsep tersebut lebih baik daripada UOB Buana. Hal ini dikarenakan adanya pergantian sistem dan kepemilikan di UOB Buana yang bisa dibilang baru, sehingga menyebabkan pergantian manajemen operasional di dalam bank tersebut. Hal ini didukung dengan pernyataan staf UOB Buana cabang Kelapa Gading bahwa ada beberapa divisi dan unit kerja yang memiliki tugas dan kewajiban yang sama, bahkan mempunyai dua buah serikat karyawan dengan fungsi yang sama.

Kedua, persepsi staf kedua bank mengenai penggunaan email juga serupa, bahwa email mempunyai kelemahan dan kelebihan namun masih merupakan media internal yang efektif sekarang ini. Walaupun email mempunyai potensi untuk menyebabkan kesalahpahaman, kelebihan email yang cepat dapat menutupi kelemahan ini. Begitu pula dengan tersedianya media internal lainnya yang dapat digunakan jika situasi membutuhkan. Para staf di kedua bank sudah memahami jika memang diperlukan komunikasi tatap muka, mereka akan menggunakan media lainnya selain email untuk menghindari kesalahpahaman.

\section{DAFTAR PUSTAKA}

Bartels, J., Peters, O., \& van der Molen, M. (2010). Horizontal and vertical communication as determinants of professional and organisational identification. Personnel Review , 210-226.

Hewitt, P. (2006). Electronic Mail and Internal Communication: A Three-Factor Model. Corporate Communications: An International Journal , 11, 78-92.

Papasolomou, I., \& Vrontis, D. (2006). Building corporate branding through internal marketing: the case of the UK retail bank industry. Journal of Product \& Brand Management , 37-47.

Shekary, G. A., Moghadam, S. K., Adaryany, N. R., \& Moghadam, I. H. (2012). The impact of internal marketing on organizational commitment in banking industry through structural equation modelling. Interdisciplinary Journal of Contemporary Research in Business , 18-27. 
Steyn, E., Steyn, D., \& van Rooyen, M. (2011). Communication at DaimlerChrysler South Africa: A Qualitative Perspective on Two-Way Symmetrical Communication and Internal Marketing. Journal of Marketing Development and Competitiveness , 5, 131-144.

Welch, M., \& Jackson, P. R. (2007). Rethinking Internal Communication: A Stakeholder Approach. Corporate Communications: An International Journal , 12, 177-198. 